\title{
What do babies eat? Evaluation of a food frequency questionnaire to assess the diets of infants aged 12 months
}

\author{
Lynne D Marriott ${ }^{1}$, Hazel M Inskip ${ }^{1}$, Sharon E Borland ${ }^{1}$, Keith M Godfrey ${ }^{1}$, \\ Catherine M Law ${ }^{2}$, Sian M Robinson ${ }^{1, *}$ and The Southampton Women's Survey \\ Study Group \\ ${ }^{1}$ MRC Epidemiology Resource Centre, University of Southampton, Southampton SO 16 6YD, UK: ${ }^{2}$ Centre for \\ Paediatric Epidemiology and Biostatistics, UCL Institute of Child Health, London, UK
}

Submitted 10 January 2008: Accepted 7 July 2008: First published online 15 August 2008

\begin{abstract}
Objective: To evaluate the relative validity of an FFQ for assessing nutrient intakes in 12-month-old infants.

Design and setting: The FFQ was developed to assess the diets of infants born to women in the Southampton Women's Survey (SWS), a population-based survey of young women and their offspring. The energy and nutrient intakes obtained from an interviewer-administered FFQ were compared with those obtained from $4 \mathrm{~d}$ weighed diaries (WD).

Subjects and methods: A sub-sample of fifty infants (aged 1 year) from the SWS had their diets assessed by both methods. The FFQ recorded the frequencies and amounts of foods and drinks consumed by the infants over the previous $28 \mathrm{~d}$; milk consumption was recorded separately. The WD recorded the weights of all foods and drinks consumed by the infants on $4 \mathrm{~d}$ following the FFQ completion.

Results: The Spearman rank correlation coefficients for intakes of energy, macronutrients and eighteen micronutrients, determined by the two methods, ranged from $r=0 \cdot 25$ to $0 \cdot 66$. Bland-Altman statistics showed that mean differences between methods were in the range $+5 \%$ to $+60 \%$ except for vitamin D $(+106 \%)$. Differences in micronutrient intake were partly explained by changes in patterns of milk consumption between the two assessments.

Conclusion: Although there were differences in absolute energy and nutrient intakes between methods, there was reasonable agreement in the ranking of intakes. The FFQ is a useful tool for assessing energy and nutrient intakes of healthy infants aged around 12 months.
\end{abstract}

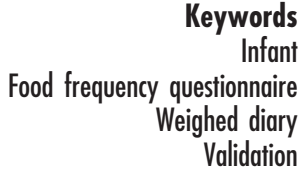

eywords
Infant

Validation
The determination of energy and nutrient intakes during infancy and childhood is important for the evaluation of the impact of diet on growth, development and long-term health. Various methods have been used to assess the dietary intakes of infants and toddlers ${ }^{(1)}$. FFQ are particularly useful for establishing generalised patterns of food intake but with the exception of a few recent studies ${ }^{(2-5)}$ have not been widely used to assess dietary intakes of infants and/or young children.

We have previously described an FFQ for dietary assessment at 6 months of age ${ }^{(6)}$. In the present paper, we evaluate the use of an interviewer-administered FFQ to assess the diets of infants aged 12 months, for use in a large population survey (the Southampton Women's Survey (SWS)), that would describe dietary patterns, and would rank infants in terms of their nutrient intake. In a sample of SWS infants, we compare energy and nutrient intakes assessed by the FFQ with intakes determined from $4 \mathrm{~d}$ weighed diaries (WD).

\section{Subjects and methods}

\section{Subjects}

The study was set within the SWS ${ }^{(7)}$, in which non-pregnant women were recruited, then followed through their subsequent pregnancy and the offspring followed up. The SWS study population of infants born between 1998 and 2003 comprised 1973 infants. Of these, 1618 (82\%) were visited within 2 weeks before and 3 weeks after their first birthday when diet was assessed. After stratification by current breastfeeding status and infant sex, a random number system was used to select ninety-eight families to participate in a weighed intake study between September 2001 and April 2003. In total, sixty-four (65\%) families approached agreed to participate in the study; fifty (51\%) successfully completed the WD.

\section{The FFQ}

Foods were included in the $\mathrm{FFQ}^{(8)}$ following review of data from a UK survey of children aged 18 months $^{(9)}, 24 \mathrm{~h}$ 
recalls collected from the mothers attending a baby clinic, and the food diaries of 12-month-old preterm infants ${ }^{(10)}$. The FFQ assesses intakes of meat, fish, vegetables, fruit, cereals, breads, cheese, eggs, vegetarian foods, puddings, spreads and snack foods (fifty-eight categories), ten categories of commercial baby foods (sub-divided by brand), and ten types of non-milk drinks. The frequency of consumption and the amount consumed over the previous $28 \mathrm{~d}$ of each food in the seventy-eight-item FFQ are recorded. Prompt cards are used to show the foods included in each food group, to ensure standardised responses to the FFQ. Portion size is described using household measures and food models. At the end of the FFQ, an open section in the same format is included, to record frequencies of consumption and amounts of any foods that were not listed on the FFQ, if consumed once per week or more. Human milk, baby formula and other milk intakes are recorded in a separate section.

\section{The weighed diary}

A $4 \mathrm{~d}$ WD was used to assess the relative validity of the 12-month FFQ, to be consistent with the diary lengths chosen for recent dietary intake studies ${ }^{(11-13)}$, and because calculations of inter-individual and intra-individual variation from energy intake data from a previous $7 \mathrm{~d}$ WD study for infants aged 12 months ${ }^{(10)}$ showed that $4 \mathrm{~d}$ would classify more than $75 \%$ of infants into the correct quintile of intake at this age. All non-human milks, foods and drinks consumed by the infant on each of $4 \mathrm{~d}$ were recorded by weight and cooking method. Each WD was completed after the FFQ. The methods for FFQ and WD collection resembled those reported for the evaluation of the 6-month $\mathrm{FFQ}^{(6)}$.

\section{Dietary analysis}

For the FFQ and WD, human milk intake was estimated using an algorithm based on length of suckling, derived from published intake data ${ }^{(14,15)}$. Nutritional composition information for infant formulas and commercial baby foods was obtained from manufacturers and/or by calculation from ingredients; and for non-baby products was taken from The Composition of Foods, 5th edition and supplements ${ }^{(16)}$. Nutrient intakes from dietary supplements were excluded.

\section{Statistical methods}

Spearman's rank correlation coefficients were used to summarise the association between the two assessments of each dietary variable. All nutrients were then adjusted for energy intake using the method of Willett ${ }^{(17)}$ and the correlation coefficients recalculated. The Bland-Altman plots $^{(18)}$ were produced to assess the level of agreement between the two methods. As the distributions of all nutrients were skewed, logarithmic transformations were used prior to the Bland-Altman analysis; the BlandAltman limits of agreement are expressed as symmetric percentages, which summarise the percentage differences between the FFQ and the WD intakes ${ }^{(19)}$.

\section{Etbical approval}

Ethical approval was granted by Southampton \& South West Hants Local Research Ethics Committee.

\section{Results}

The characteristics of the fifty mother-infant pairs studied were comparable with the remainder of the SWS cohort ${ }^{(8)}$ ( $P>0.05$ for all comparisons; Table 1$)$. The median (interquartile range, IQR) interval between FFQ completion and the beginning of the WD was 7 (4-10) d; $72 \%$ of diaries were completed on four consecutive days.

\section{Comparison of FFQ with WD intake}

In general, intakes assessed by the FFQ were higher than WD-assessed intakes, but the correlation coefficients $(r)$

Table 1 Characteristics of mother-infant pairs in weighed diary sub-sample and remainder of the cohort born by end of $2003^{(8)}$

\begin{tabular}{|c|c|c|c|c|}
\hline \multirow[b]{2}{*}{ Characteristics } & \multicolumn{2}{|c|}{ Weighed diary group ( $n 50)$} & \multicolumn{2}{|c|}{ Remainder of cohort ( $n$ 1582) } \\
\hline & $n$ or median & $\%$ or IQR & $n$ or median & $\%$ or IQR \\
\hline \multicolumn{5}{|l|}{ Maternal } \\
\hline \multicolumn{5}{|l|}{ Educational qualifications } \\
\hline GCSE grade D or below & 7 & 14 & 200 & 13 \\
\hline GCSE grade $\mathrm{C}$ to HND & 28 & 56 & 1024 & 66 \\
\hline University degree or above & 15 & 30 & 331 & 21 \\
\hline Age at child's birth (years) & 30 & $27-32$ & 30 & $27-33$ \\
\hline $\mathrm{BMI}$, pre-pregnant $\left(\mathrm{kg} / \mathrm{m}^{2}\right)$ & $24 \cdot 9$ & $22 \cdot 5-29 \cdot 8$ & $24 \cdot 3$ & $22 \cdot 0-27 \cdot 7$ \\
\hline Smoker, pre-pregnant & 8 & 16 & 432 & 28 \\
\hline \multicolumn{5}{|l|}{ Infant } \\
\hline Sex: female & 23 & 46 & 743 & 47 \\
\hline Birth weight $(\mathrm{kg})$ & 3.50 & $3 \cdot 08-3 \cdot 78$ & $3 \cdot 47$ & $3 \cdot 15-3 \cdot 81$ \\
\hline Weight at FFQ (kg) & $9 \cdot 92$ & $9 \cdot 18-10 \cdot 52$ & $9 \cdot 96$ & $9 \cdot 28-10 \cdot 80$ \\
\hline \multicolumn{5}{|l|}{ Birth order } \\
\hline First & 23 & 46 & 724 & 46 \\
\hline Second & 18 & 36 & 589 & 38 \\
\hline Third or later & 9 & 18 & 245 & 16 \\
\hline Still breastfed at FFQ & 7 & 14 & 156 & 10 \\
\hline
\end{tabular}

IQR, interquartile range; GCSE, general certificate of secondary education; HND, higher national diploma. 
Table 2 Energy and nutrient intakes from all foods and drinks, FFQ and WD, the Spearman rank correlation coefficients $(r)$, energyadjusted correlation coefficients $\left(r^{\mathrm{a}}\right)$ and Bland-Altman statistics

\begin{tabular}{|c|c|c|c|c|c|c|c|c|}
\hline \multirow[b]{2}{*}{ Energy/nutrient } & \multicolumn{2}{|c|}{ FFQ } & \multicolumn{2}{|c|}{ WD } & \multirow[b]{2}{*}{$r^{*}$} & \multirow[b]{2}{*}{$r^{a * \star}$} & \multicolumn{2}{|c|}{ Bland-Altman } \\
\hline & Median & IQR & Median & IQR & & & $\begin{array}{c}\text { Mean difference, } \\
\text { FFQ - WD (\%) }\end{array}$ & $\begin{array}{l}\text { Limits of } \\
\text { agreement (\%) }\end{array}$ \\
\hline Energy $(\mathrm{kJ})$ & 4422 & $4044-5550$ & 3771 & $3426-4315$ & 0.46 & - & 19 & -26 to 64 \\
\hline Protein $(\mathrm{g})$ & $37 \cdot 0$ & $32 \cdot 6-52 \cdot 1$ & $34 \cdot 5$ & $28 \cdot 9-39 \cdot 4$ & 0.52 & 0.50 & 16 & -41 to 72 \\
\hline Fat $(\mathrm{g})$ & $42 \cdot 4$ & $38 \cdot 3-52 \cdot 6$ & $36 \cdot 6$ & $33 \cdot 8-46 \cdot 3$ & 0.36 & 0.35 & 14 & -45 to 72 \\
\hline Carbohydrate (g) & 135 & $117-155$ & 112 & $96-127$ & 0.49 & 0.44 & 23 & -18 to 64 \\
\hline Total sugar $(\mathrm{g})$ & $82 \cdot 3$ & $71 \cdot 3-99 \cdot 4$ & $65 \cdot 4$ & $51 \cdot 8-79 \cdot 7$ & 0.53 & 0.71 & 24 & -21 to 68 \\
\hline $\mathrm{Na}(\mathrm{mg})$ & 861 & $681-1248$ & 862 & $613-1084$ & 0.66 & 0.75 & 5 & -63 to 73 \\
\hline $\mathrm{K}(\mathrm{mg})$ & 1744 & 1410-2035 & 1402 & $1243-1641$ & 0.51 & 0.42 & 19 & -31 to 68 \\
\hline Ca (mg) & 877 & $783-978$ & 784 & $611-990$ & 0.65 & 0.61 & 12 & -42 to 65 \\
\hline $\mathrm{Mg}(\mathrm{mg})$ & 142 & $117-176$ & 129 & $103-149$ & 0.53 & 0.57 & 17 & -37 to 71 \\
\hline $\mathrm{P}(\mathrm{mg})$ & 833 & 698-1027 & 768 & $587-928$ & 0.49 & 0.58 & 13 & -44 to 69 \\
\hline $\mathrm{Fe}(\mathrm{mg})$ & 8.48 & $5 \cdot 92-10 \cdot 72$ & $5 \cdot 20$ & $3 \cdot 96-7 \cdot 40$ & 0.44 & 0.50 & 46 & -37 to 128 \\
\hline $\mathrm{Zn}(\mathrm{mg})$ & $6 \cdot 25$ & $5 \cdot 37-7 \cdot 40$ & $4 \cdot 54$ & $3.97-5 \cdot 48$ & 0.39 & 0.48 & 31 & -26 to 88 \\
\hline $\mathrm{Cu}(\mathrm{mg})$ & 0.64 & $0.49-0.80$ & 0.43 & $0.33-0.51$ & 0.50 & 0.63 & 46 & -19 to 111 \\
\hline Retinol ( $\mu \mathrm{g})$ & 569 & $474-657$ & 400 & $329-547$ & $0 \cdot 48$ & 0.58 & 27 & -37 to 92 \\
\hline Vitamin $D(\mu \mathrm{g})$ & $6 \cdot 29$ & $3 \cdot 93-7 \cdot 97$ & 1.54 & $0.75-4.55$ & 0.43 & 0.40 & 106 & -89 to 301 \\
\hline Vitamin E (mg) & $6 \cdot 13$ & $4 \cdot 92-6 \cdot 92$ & $4 \cdot 11$ & $2 \cdot 67-5 \cdot 26$ & 0.25 & 0.27 & 45 & -42 to 132 \\
\hline Thiamin (mg) & 0.96 & $0 \cdot 74-1 \cdot 32$ & $0 \cdot 75$ & $0.59-0.92$ & 0.55 & 0.53 & 28 & -39 to 96 \\
\hline Riboflavin (mg) & $1 \cdot 70$ & $1 \cdot 37-1 \cdot 90$ & $1 \cdot 43$ & $1 \cdot 13-1 \cdot 83$ & 0.48 & 0.51 & 14 & -46 to 74 \\
\hline Niacin (mg) & $10 \cdot 52$ & $7 \cdot 81-13 \cdot 83$ & $7 \cdot 48$ & $5 \cdot 30-9 \cdot 18$ & 0.59 & 0.60 & 43 & -28 to 114 \\
\hline Vitamin $B_{6}(\mathrm{mg})$ & 1.09 & $0 \cdot 86-1 \cdot 36$ & 0.81 & $0 \cdot 70-1 \cdot 17$ & 0.62 & 0.54 & 23 & -36 to 83 \\
\hline Folic acid $(\mu \mathrm{g})$ & 143 & $125-181$ & 112 & $87-137$ & 0.39 & 0.31 & 29 & -35 to 94 \\
\hline Vitamin $B_{12}(\mu \mathrm{g})$ & 3.08 & $2 \cdot 48-4 \cdot 04$ & $2 \cdot 80$ & $2 \cdot 12-3 \cdot 60$ & 0.42 & 0.24 & 13 & -69 to 94 \\
\hline Vitamin $C(\mathrm{mg})$ & $79 \cdot 6$ & $58 \cdot 2-108 \cdot 6$ & $42 \cdot 3$ & $26 \cdot 3-62 \cdot 8$ & 0.52 & 0.47 & 60 & -46 to 166 \\
\hline
\end{tabular}

WD, weighed diary; IQR, interquartile range.

${ }^{*}$ All $P<0.01$ except fat $P=0.01$ and vitamin E $P=0.08$

${ }^{\star *}$ All $P<0.01$ except fat $P=0.01$, vitamin $\mathrm{E} P=0.06$, vitamin $\mathrm{B}_{12} P=0.079$, folic acid $P=0.03$.

Table 3 Types of milk used at the FFQ and the WD assessments

\begin{tabular}{lrrrrr}
\hline & \multicolumn{2}{c}{ At FFQ collection } & & \multicolumn{2}{c}{ At WD collection } \\
\cline { 2 - 3 } \cline { 5 - 6 } Type of milk used & $n$ & $\%$ & 16 & 5 & $\%$ \\
\hline Human milk & 8 & 80 & 20 & 10 \\
Baby milk formulas & 40 & 92 & 47 & 40 \\
Cow's milk (including other animal milks) & 46 & & & 94 \\
\hline
\end{tabular}

WD, weighed diary

Note: Total $>100 \%$ because many infants consumed more than one type of milk.

demonstrated comparable rankings of intakes from the two methods. The coefficients ranged from $r=0 \cdot 25$ (vitamin E) to $0 \cdot 66(\mathrm{Na})$ (Table 2$)$. The range of correlation coefficients for micronutrients tended to be wider than that for energy and macronutrients $(0 \cdot 36$ (fat) to 0.52 (protein)). Adjustment for energy intake had little effect on the levels of correlation, range, $r^{\mathrm{a}}=0 \cdot 24-0.75$ (Table 2).

In the comparison of absolute intakes of energy and nutrients assessed by the FFQ and the WD, all mean differences (MD) were positive, and within the range of $5 \%$ to $60 \%$ except for vitamin D (106\%) (Table 2). The median energy/kg body weight was $450 \mathrm{~kJ}$ (FFQ) and $387 \mathrm{~kJ}$ (WD).

\section{Exploration of differences between FFQ and weighed diary}

At 1 year, milk still comprises a substantial part of the diet for most infants; the median (IQR) energy intake derived from milks in the diet was $37 \%(27-45 \%)$ from the FFQ and $38 \%$ (25-45\%) from the WD. Although the energy derived from milks was very similar for both methods, there were changes in the patterns of milk feeding between the periods assessed by the FFQ and the WD (Table 3). Eleven infants (22\%) changed from consuming a baby milk formula as their main milk to consuming only cow's milk during WD collection. We defined these eleven infants as 'major milk changers'.

Since there are substantial differences in the nutritional composition between formula milks and cow's milk (including much higher levels of $\mathrm{Fe}, \mathrm{Cu}$, vitamins $\mathrm{C}, \mathrm{D}, \mathrm{E}$ and niacin in formula milks), we compared nutrient intakes assessed by the FFQ and the WD from foods and drinks other than milks (referred to as 'non-milk' foods and drinks). Comparison of nutrients from non-milk foods and drinks assessed by the FFQ and the WD (Table 4) generally yielded higher correlation coefficients (range $0 \cdot 44-0 \cdot 70$ ) than those found for the whole diet, 
Table 4 Energy and nutrient intakes from foods and drinks other than milks, FFQ and WD, the Spearman rank correlation coefficients ( $r$ ) and Bland-Altman statistics

\begin{tabular}{|c|c|c|c|c|c|c|c|}
\hline \multirow{3}{*}{ Energy/nutrient } & \multicolumn{2}{|c|}{ FFQ } & \multicolumn{2}{|c|}{ WD } & \multirow{3}{*}{$r^{*}$} & \multicolumn{2}{|c|}{ Bland-Altman } \\
\hline & & > & Median & > & & Mean difference, & $\begin{array}{l}\text { Limits of } \\
\text { agreement }\end{array}$ \\
\hline & Median & IQR & Miedian & IQR & & & \\
\hline Energy (kJ) & 2698 & 2276-3749 & 2352 & $1921-2890$ & 0.65 & 20 & -34 to 73 \\
\hline Protein $(\mathrm{g})$ & $23 \cdot 9$ & $19 \cdot 4-36 \cdot 4$ & $20 \cdot 4$ & $15 \cdot 9-25 \cdot 8$ & 0.70 & 25 & -36 to 86 \\
\hline Fat $(\mathrm{g})$ & $21 \cdot 4$ & $17 \cdot 1-31 \cdot 1$ & $18 \cdot 0$ & $14 \cdot 9-23 \cdot 7$ & 0.44 & 16 & -60 to 92 \\
\hline Carbohydrate $(\mathrm{g})$ & $89 \cdot 8$ & $77 \cdot 8-116 \cdot 3$ & $78 \cdot 8$ & $63 \cdot 8-101 \cdot 8$ & 0.67 & 20 & -30 to 70 \\
\hline Total sugar $(\mathrm{g})$ & $43 \cdot 6$ & $33 \cdot 5-54 \cdot 6$ & $37 \cdot 3$ & $28 \cdot 8-44 \cdot 4$ & $0 \cdot 66$ & 20 & -35 to 75 \\
\hline $\mathrm{Na}(\mathrm{mg})$ & 665 & $439-938$ & 596 & $465-853$ & $0 \cdot 70$ & 9 & -68 to 86 \\
\hline $\mathrm{K}(\mathrm{mg})$ & 1080 & $830-1401$ & 820 & $640-951$ & 0.65 & 30 & -26 to 86 \\
\hline $\mathrm{Ca}(\mathrm{mg})$ & 346 & $290-448$ & 287 & $225-385$ & 0.59 & 25 & -46 to 96 \\
\hline $\mathrm{Mg}(\mathrm{mg})$ & $89 \cdot 6$ & $79 \cdot 6-136 \cdot 5$ & $74 \cdot 6$ & $59 \cdot 8-96 \cdot 6$ & $0 \cdot 64$ & 27 & -31 to 84 \\
\hline$P(\mathrm{mg})$ & 444 & $365-637$ & 333 & $298-448$ & 0.58 & 26 & -36 to 88 \\
\hline $\mathrm{Fe}(\mathrm{mg})$ & $4 \cdot 42$ & $3 \cdot 28-6 \cdot 80$ & 3.97 & $3 \cdot 14-4 \cdot 93$ & 0.58 & 20 & -54 to 95 \\
\hline $\mathrm{Zn}(\mathrm{mg})$ & $2 \cdot 70$ & $2 \cdot 14-4 \cdot 12$ & 2.09 & $1 \cdot 82-2 \cdot 99$ & 0.66 & 26 & -36 to 88 \\
\hline $\mathrm{Cu}(\mathrm{mg})$ & $0 \cdot 46$ & $0.34-0.59$ & 0.34 & $0 \cdot 26-0.42$ & 0.46 & 33 & -36 to 112 \\
\hline Retinol $(\mu \mathrm{g})$ & 172 & $118-253$ & 124 & $97-168$ & 0.56 & 34 & -74 to 142 \\
\hline Vitamin D $(\mu \mathrm{g})$ & 0.90 & $0.48-1.58$ & 0.57 & $0 \cdot 36-1 \cdot 24$ & 0.59 & 33 & -108 to 174 \\
\hline Vitamin E (mg) & $2 \cdot 93$ & $2 \cdot 01-3 \cdot 70$ & $2 \cdot 49$ & $1 \cdot 81-3 \cdot 18$ & 0.38 & 13 & -81 to 107 \\
\hline Thiamin (mg) & 0.59 & $0.44-0.89$ & 0.48 & $0.39-0.68$ & 0.58 & 27 & -53 to 107 \\
\hline Riboflavin (mg) & 0.87 & $0.58-1.04$ & 0.67 & $0.48-0.85$ & 0.52 & 21 & -51 to 93 \\
\hline Niacin (mg) & $6 \cdot 83$ & $4 \cdot 66-10 \cdot 40$ & $6 \cdot 15$ & $3 \cdot 92-7 \cdot 18$ & 0.64 & 28 & -53 to 110 \\
\hline Vitamin $\mathrm{B}_{6}(\mathrm{mg})$ & 0.74 & $0.55-1.10$ & 0.60 & $0.38-0.75$ & 0.69 & 31 & -42 to 103 \\
\hline Folic acid $(\mu \mathrm{g})$ & $100 \cdot 0$ & $75 \cdot 9-138 \cdot 1$ & $77 \cdot 2$ & $60 \cdot 2-102 \cdot 3$ & 0.61 & 28 & -44 to 99 \\
\hline Vitamin $B_{12}(\mu \mathrm{g})$ & $1 \cdot 79$ & $1 \cdot 21-2 \cdot 46$ & $1 \cdot 30$ & $0.75-1.66$ & 0.44 & 35 & -80 to 150 \\
\hline Vitamin C (mg) & $39 \cdot 4$ & $26 \cdot 5-56 \cdot 2$ & $24 \cdot 8$ & $17 \cdot 9-35 \cdot 7$ & 0.58 & 43 & -66 to 152 \\
\hline
\end{tabular}

WD, weighed diary; IQR, interquartile range.

${ }^{*}$ All $P<0.001$ except fat $P=0.0013$, vitamin $\mathrm{E} P=0.007$ and vitamin $\mathrm{B}_{12} P=0.0015$.

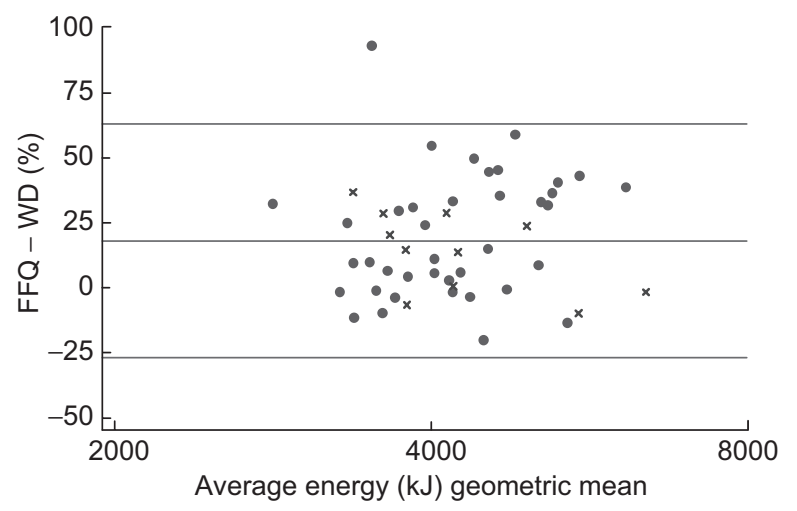

Fig. 1 The Bland-Altman plot for energy intake, according to whether there was a major milk change or not $(\bullet$, no major milk change; $\times$, major milk change). WD, weighed diary

with the exceptions of $\mathrm{Ca}$ and $\mathrm{Cu}$ (Table 4). Similarly, the range of MD was narrowed to $9-43 \%$, and for those six nutrients present at high levels in formulas compared with cow's milk, the MD were lower than those for the whole diet. For the eleven infants denoted as major milk changers, the differences in composition between cow's milk and formulas were associated with a wider distribution of points in the Bland-Altman plots for the six nutrients specified above. The Bland-Altman plots for energy and Fe are shown in Figs 1 and 2. The effect of a major change in milk feeding on intakes is illustrated in the plot for $\mathrm{Fe}$, a mineral frequently cited as present in sub-optimal quantities in the diets of older infants ${ }^{(20)}$.

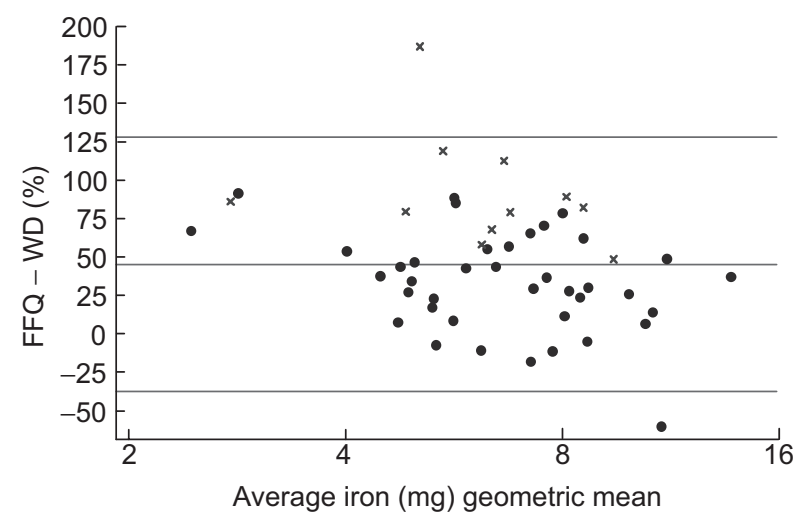

Fig. 2 The Bland-Altman plot for iron intake, according to whether there was a major milk change or not $(\bullet$, no major milk change; $\times$, major milk change). WD, weighed diary

\section{Discussion}

We have compared the dietary intakes assessed by a newly developed FFQ with those assessed by WD at around 12 months of age. Although the FFQ-assessed intakes tended to be higher than those from the WD, there was reasonable to good ranking of intakes for most nutrients.

The WD was completed after the FFQ. Because of the changes in milk feeding around 12 months of age, we considered nutrient intakes from non-milk foods and drinks as well as nutrients from the whole diet. The rank correlation coefficients for nutrients from non-milk foods 
and drinks were generally higher than those for nutrients from the whole diet, with the majority of correlation coefficients above $\mathbf{0 \cdot 5}$. Given the importance of milk as a component of the diet for most infants and the very different nutrient compositions of formulas $v$. cow's milk, this may indicate that the differences in nutrient intakes between methods for those micronutrients present at high levels in formulas that we observed, were greater than they would have been if the FFQ and the WD had assessed diet over the same period. Similarly, the range of Bland-Altman MD (\%) was smaller for nutrients from non-milk foods and drinks than nutrients from the whole diet, suggesting that the differences were influenced by changes in the pattern of milk consumption between the periods assessed by the FFQ and the WD.

\section{Comparison with other studies}

We are not aware of any other FFQ validation studies of energy and nutrient intakes at 1 year of age from the UK. However, our correlation coefficients were comparable with those from other FFQ relative validation studies for young children from countries which might be expected to have similar feeding practices to those in the $\mathrm{UK}^{(3-5,21)}$. Although our FFQ measures of intake were higher than those from the WD, the MD (\%) between the FFQ and the WD for energy and macronutrients were all less than $25 \%$, and both the FFQ and the WD produced median energy intakes (450 v.387 kJ/kg, respectively) that were higher than the energy requirements/kg for 12-month-old infants derived from doubly labelled ${ }^{(22)}$ studies $(334 \mathrm{~kJ})$. Higher FFQ-assessed intakes in infants have been noted by Andersen $^{(3)}$, who reported a difference of $25 \%$ in energy intakes between a semi-quantitative FFQ and $7 \mathrm{~d}$ weighed record in Norwegian children at 1 year. These differences in intakes between methods may arise from difficulties in describing portion size and/or frequency in response to the $\mathrm{FFQ}^{(3)}$.

\section{Strengths and weaknesses}

We studied a stratified random sample of infants, who were representative of the SWS population, which in turn is comparable to the UK population ${ }^{(7)}$. The quality of the information in our FFQ was enhanced by collecting data over a short recall period, recording both brand information and amount and frequency of consumption of all foods and drinks, and the use of trained personnel to administer the questionnaire.

A weakness of our study is that the WD was completed after the FFQ was administered. Although the interval between dietary assessments was short there were significant changes in patterns of milk consumption over this time that may have led to an underestimation of the level of agreement between the FFQ and the WD. In the absence of an alternative feasible method and in common with other UK infant dietary studies ${ }^{(14,23)}$, both the FFQ and WD estimated human milk intake using an algorithm relating length of suckling to intake; this could have also contributed to the overestimation in intakes in our study.

\section{Conclusion}

The FFQ is appropriate for use in large epidemiological studies and is a useful instrument for the assessment of infant diet at around 1 year of age. The comparison of nutrient intakes assessed by the FFQ and the WD showed that the ranking of infants according to nutrient intake was comparable for both methods. While there were differences between methods in estimates of energy and nutrient intakes, the magnitudes of the differences were small to moderate for energy and macronutrients. The level of agreement between methods was influenced by the effect of a change in infants' milk consumption in the period between assessments, and may be underestimated in our study.

\section{Acknowledgements}

Funding support: The SWS has received support from the UK Medical Research Council, University of Southampton, Dunhill Medical Trust, the British Heart Foundation and the Food Standards Agency.

Conflict of interest: None of the authors has any conflicting interests.

Authors' contributions: S.E.B. devised the FFQ; H.M.I., K.M.G., C.M.L., S.M.R. and L.D.M. planned the diary study; L.D.M. carried out the fieldwork and, with S.M.R., was responsible for the nutritional analysis; H.M.I. performed the statistical analysis. L.D.M. wrote the first draft of the manuscript with contributions from all individual authors.

Acknowledgements: We are grateful to the SWS families who have given information to the survey. We thank the SWS nurses for data collection, Ken Cox, Patsy Coakley and Vanessa Cox for managing the data, and the SWS Study Group for their help.

\section{References}

1. Serdula MK, Alexander MP, Scanlon KS \& Bowman BA (2001) What are preschool children eating? A review of dietary assessment. Annu Rev Nutr 21, 475-498.

2. Klohe DM, Clarke KK, George GC, Milani TJ, Hanss-Nuss H \& Freeland-Graves J (2005) Relative validity and reliability of a food frequency questionnaire for a triethnic population of 1-year-old to 3-year-old children from low-income families. J Am Diet Assoc 105, 727-734.

3. Andersen LF, Lande B, Arsky GH \& Trygg K (2003) Validation of a semi-quantitative food-frequency questionnaire used among 12-month-old Norwegian infants. Eur J Clin Nutr 57, 881-888.

4. Parrish LA, Marshall JA, Krebs NF, Rewers M \& Norris JM (2003) Validation of a food frequency questionnaire in preschool children. Epidemiology 14, 213-217.

5. Blum RE, Wei EK, Rockett HRH, Langliers JD, Leppert J, Gardner JD \& Colditz GA (1999) Validation of a food frequency questionnaire in Native American and Caucasian 
children 1 to 5 years of age. Matern Child Health J 3, $167-172$.

6. Marriott LD, Robinson SM, Poole J, Borland SE, Godfrey KM, Law CM, Inskip HM \& The SWS Study Group (2008) What do babies eat? Evaluation of a food frequency questionnaire to assess the diets of infants aged 6 months. Public Health Nutr 11, 751-756.

7. Inskip HM, Godfrey KM, Robinson SM, Law CM, Barker DJP, Cooper C \& The SWS Study Group (2006) Cohort profile: The Southampton Women's Survey. Int J Epidemiol 35, 42-48.

8. Robinson S, Marriott L, Poole J, Crozier S, Borland S, Lawrence W, Law C, Godfrey K, Cooper C, Inskip H \& The SWS Study Group (2007) Dietary patterns in infancy: the importance of maternal and family influences on feeding practice. Br J Nutr 98, 1029-1037.

9. Gregory JR, Collins DL, Davies PSW, Hughes JM \& Clarke PC (1995) National Diet and Nutrition Survey: Children Aged 1.5 to 4.5 Years. vol. 1: Report of the Diet and Nutrition Survey. London: HMSO.

10. Marriott LD, Foote KD, Bishop JA, Kimber AC \& Morgan JB (2003) Weaning preterm infants: a randomised controlled trial. Arch Dis Child 88, F302-F307.

11. Lanigan JA, Wells JCK, Lawson MS \& Lucas A (2001) Validation of food diary method for assessment of dietary energy and macronutrient intake in infants and children aged 6-24 months. Eur J Clin Nutr 55, 124-129.

12. Lagstrom H, Jokinen E, Seppanen R et al. (1997) Nutrient intakes by young children in a prospective randomized trial of a low-saturated fat, low-cholesterol diet. The STRIP Baby Project. Arch Pediatr Adolesc Med 151, 181-188.

13. Heinig MJ, Nommsen LA, Peerson JM, Lonnerdal B \& Dewey KG (1993) Intake and growth of breast-fed and formula-fed infants in relation to the timing of introduction of complementary foods: The DARLING Study. Acta Paediatr 82, 999-1006.

14. Mills A \& Tyler H (1992) Food and Nutrient Intakes of British Infants Aged 6-12 Months. London: HMSO.

15. Paul AA, Black AE, Evans J, Cole TJ \& Whitehead RG (1988) Breastmilk intake and growth in infants from two to ten months. J Hum Nutr Diet 1, 437-450.

16. Holland B, Welch AA, Unwin ID, Buss DH, Paul AA \& Southgate DAT (1991) The Composition of Foods, 5th ed. Cambridge: The Royal Society of Chemistry.

17. Willett W (1998) Nutritional Epidemiology, 2nd ed. Oxford: Oxford University Press.

18. Bland JM \& Altman DG (1986) Statistical methods for assessing agreement between two methods of clinical measurement. Lancet i, 307-310.

19. Cole TJ (2000) Sympercents: symmetric percentage differences on the $100 \log _{\mathrm{e}}$ scale simplify the presentation of log transformed data. Stat Med 19, 3109-3135.

20. Hopkins D, Emmett P, Steer C, Rogers I, Noble S \& Emond A (2007) Infant feeding in the second 6 months of life related to iron status: an observational study. Arch Dis Child 92, 850-854.

21. Williams PL \& Innis SM (2005) Food frequency questionnaire for assessing infant iron nutrition. Can J Diet Pract Res 66, 176-182.

22. Butte NF (2005) Energy requirements of infants. Public Health Nutr 8, 953-967.

23. Ong KK, Emmett PM, Noble S, Ness A, Dunger DB \& The ALSPAC Study Team (2006) Dietary energy intake at the age of 4 months predicts postnatal weight gain and childhood body mass index. Pediatrics 117, e503-e508. 